\title{
PARTICIPAÇÃO MASCULINA NO PLANEJAMENTO FAMILIAR: O QUE PENSAM AS MULHERES?*
}

\author{
Ana Cláudia Brito de Morais¹, Rachel de Sá Barreto Luna Callou Cruz², Sarah de Lima Pinto ${ }^{3}$ \\ Ludwig Tenório Cruz Gomes Amorim4, Karla Jimena de Araújo Jesus Sampaio ${ }^{5}$
}

'Enfermeira. Especialista em Saúde da Família. Universidade Regional do Cariri. Crato-CE-Brasil.

${ }^{2}$ Enfermeira. Doutoranda em Saúde Materno Infantil. Instituto de Medicina Integral Prof. Fernando Figueira. Recife-PE-Brasil. ${ }^{3}$ Enfermeira. Mestre em Desenvolvimento Regional Sustentável. Universidade Regional do Cariri. Crato-CE-Brasil.

${ }^{4}$ Discente de Medicina. Faculdade Pernambucana de Saúde. Recife-PE-Brasil.

${ }^{5}$ Enfermeira. Doutora em Ciências. Universidade Regional do Cariri. Crato-CE-Brasil.

RESUMO: Trata-se de pesquisa descritiva com abordagem qualitativa, cujo objetivo foi conhecer a percepção feminina sobre a participação dos homens no planejamento familiar. Entrevistou-se 20 mulheres no período de fevereiro a julho de 2012, em uma unidade de referência em assistência reprodutiva, no Ceará. A partir das alocuções emergiram duas categorias: Contribuição do companheiro na contracepção e $O$ que as mulheres pensam sobre a participação do homem no planejamento familiar? As mulheres percebem a participação do homem como insuficiente e acreditam que uma contribuição mais efetiva incluiria a ida do companheiro às consultas. Reconhecem ser importante essa contribuição, mas algumas mostram aceitação diante da ausência do homem, não cobrando esse envolvimento. Ao escolher sozinha e se responsabilizar pela contracepção a mulher exime o parceiro de uma atribuição que é de ambos, reforçando a idéia socialmente construída, e aceita, consciente ou inconscientemente, de que são encarregadas dos assuntos reprodutivos.

DESCRITORES: Planejamento familiar; Percepção; Gênero.

\section{MEN'S PARTICIPATION IN FAMILY PLANNING: WHAT DO THE WOMEN THINK?}

\begin{abstract}
This is descriptive research with a qualitative approach, which aimed to investigate women's perception regarding male participation in family planning. Interviews were held with 20 women in February - July 2012, in a center of excellence in reproductive care, in the state of Ceará. Two categories emerged from the accounts: The partner's contribution in contraception and What do women think regarding the man's participation in family planning? The women perceive the men's participation as insufficient, and believe that a more effective contribution would include the partners accompanying them to the consultations. They recognize this contribution as important, but some show acceptance in relation to the man's absence, and do not demand this involvement. In making their selections on their own, and taking responsibility for the contraception, the women absolve the partners from an attribution which is of both, reinforcing the socially constructed and - consciously or unconsciously - accepted idea that it is they who are given responsibility for reproductive matters.
\end{abstract}

DESCRIPTORS: Family planning; Perception; Gender.

\section{PARTICIPACIÓN MASCULINA EN EL PLANEAMIENTO FAMILIAR: ¿LO QUÉ PIENSAN LAS MUJERES?}

RESUMEN: Esta es una investigación descriptiva con abordaje cualitativo, cuyo objetivo fue conocer la percepción femenina acerca de la participación de los hombres en el planeamiento familiar. Fueron entrevistadas 20 mujeres en el periodo de febrero a julio de 2012, en una unidad de referencia en asistencia reproductiva, en Ceará. Resultaron de las charlas dos categorías: Contribución del compañero en la contracepción y ¿Qué las mujeres piensan acerca de la participación del hombre en el planeamiento familiar? Las mujeres perciben la participación del hombre como insuficiente y creen que una contribución más efectiva llevaría el compañero a las consultas. Reconocen ser importante esa contribución, pero algunas aceptan la ausencia del hombre, no cobrando su participación. Al hacer opciones sola y responsabilizarse por la contracepción, la mujer exime el compañero de una atribución que es de los dos, reforzando la idea socialmente construida, y acepta, de modo consciente o inconsciente, de que no tienen la responsabilidad de los asuntos reproductivos. DESCRIPTORES: Planeamiento familiar; Percepción; Género.

*Artigo extraído do trabalho de conclusão do Curso em Enfermagem intitulado: A participação masculina no planejamento familiar: o que pensam as mulheres? Universidade Regional do Cariri, 2013.

Autor Correspondente:

Rachel de Sá Barreto Luna Callou Cruz

Instituto de Medicina Integral Prof. Fernando Figueira

Rua Esperanto, n³11 - 50070-390 - Recife-PE-Brasil

E-mail: rachel.callou@hotmail.com
Recebido: $11 / 07 / 2013$

Finalizado: 15/10/2014 


\section{INTRODUÇÃO}

O planejamento familiar é definido como a prática da paternidade responsável, ou seja, a utilização voluntária e consciente, por parte do casal, do instrumento necessário à planificação do número de filhos e do espaçamento entre uma gestação e outra ${ }^{(1)}$.

Até a segunda metade do século $X X$, os serviços de saúde de assistência reprodutiva no Brasil se orientaram tradicionalmente pela política centrada exclusivamente na mulher reprodutora. A partir dos anos 1980 essa situação tomou uma nova direção com o nascimento do Programa de Atenção Integral à Saúde da Mulher (PAISM), cujos conceitos serviram como referência e inspiração para a luta pela equidade de gênero na saúde, e representam um avanço em relação à saúde da mulher, na medida em que se propõe um modelo baseado na assistência integral(2).

Entretanto, duas observações foram ressaltadas sobre o PAISM: o Programa teria ignorado a participação do homem no processo reprodutivo; e dispunha de um reduzido número de métodos contraceptivos que, em sua grande maioria, se restringiam aos métodos hormonais e à laqueadura tubária, que tecnicamente não requerem a participação masculina ${ }^{(3)}$.

O planejamento familiar, de acordo com o Ministério da Saúde é considerado como um direito que as pessoas têm de ter acesso à informação, à assistência especializada e aos recursos que permitam optar livre e conscientemente por ter ou não filhos. O número, o espaçamento entre as gestações e a escolha do método anticoncepcional mais adequado, sem discriminação, coerção ou violência, deve ser parte integrante do conjunto de ações na saúde da mulher, do homem ou do casal ${ }^{(4)}$.

No entanto, a realidade não condiz na totalidade com essa afirmação, pois na rotina dos serviços de saúde, o que se observa é a escassa participação masculina, tornando a concepção ou a contracepção encargo exclusivo da mulher ${ }^{(5)}$.

Isso evidencia o poder das relações de gênero, apontando para o papel social desempenhado pelo homem, em uma sociedade historicamente patriarcal, que impõe à mulher a responsabilidade pela contracepção( ${ }^{(6)}$.

O domínio da mulher sobre sua própria fecundidade é considerado um dos pilares do processo de seu empoderamento, recaindo, portanto, sobre o ser feminino as consequências de uma gravidez não desejada, sendo natural que ela queira assumir a tarefa de contracepção(7).

Diante do exposto, fica clara a existência de uma visão equivocada, mas socialmente construída, sobre a quem pertence a responsabilidade da anticoncepção, já que por determinação cultural, esse encargo é imposto e aceito pela mulher.

Dessa forma, há necessidade de se ter um conhecimento prévio do comportamento reprodutivo da clientela para o planejamento das ações preventivas e efetivas sobre planejamento familiar. E, aliado ao conhecimento técnico e legal, propor estratégias educativas eficazes que favoreçam a transformação de crenças, tabus e conceitos sobre o exercício da sexualidade, como um direito ligado a opção e responsabilidade de reprodução, promovendo, por fim, o despertar para a correta participação na construção familiar ${ }^{(8)}$.

Numa contribuição para esta discussão, fazse o seguinte questionamento: $O$ que pensam as mulheres sobre a participação masculina no planejamento familiar?

Acredita-se que levantar informações acerca da percepção feminina sobre a participação de seus companheiros no controle da fecundidade, contribuirá para a reformulação das ações educativas e desenvolvimento de estratégias de intervenções comportamentais, que desmistifiquem o conceito equivocado sobre responsabilidades no planejamento familiar, de forma a promover a participação igualitária do casal na decisão de concepção ou contracepção.

Nesse sentido, objetivou-se com este trabalho, conhecer o pensamento feminino sobre a participação dos homens no planejamento familiar.

\section{MÉTODOS}

O estudo foi do tipo descritivo com abordagem qualitativa, realizado no período de fevereiro a julho de 2012, no Centro Microrregional de Excelência à Assistência Reprodutiva (CEMEAR), localizado no município de Crato, Ceará.

Para a seleção das participantes, os seguintes critérios de inclusão foram utilizados: usuárias cadastradas e acompanhadas pelo serviço de 
planejamento familiar do CEMEAR; casadas civilmente ou por união consensual e em idade igual ou acima de 18 anos. As pacientes que corresponderam a esses critérios foram procuradas em seu domicílio, esclarecidas sobre a pesquisa e convidadas a participar dela.

Para delimitação dos sujeitos considerou-se o critério de saturação das respostas ${ }^{(9)}$. Com isso, obteve-se um número de 20 mulheres. A estas foi garantido o anonimato a partir da codificação individual das entrevistas, com a utilização de M1, M2, M3 e assim por diante, como forma representativa de suas participações.

Anteriormente à coleta de dados foi aplicado um pré-teste com outras usuárias cadastradas no planejamento familiar de uma Estratégia Saúde da Família no município de Crato-CE, com a finalidade de validar e identificar possíveis falhas na utilização da entrevista semiestruturada.

As entrevistas foram mediadas por um gravador portátil para otimizar a reprodução dos discursos dos entrevistados, os quais foram, posteriormente, transcritos de forma integral, possibilitando dessa forma, a fidedignidade das informações.

A interpretação qualitativa dos dados foi feita de acordo com a técnica de análise de conteúdo ${ }^{(10)}$, na qual se aplicaram duas funções. As etapas da pesquisa foram três: Pré-análise: organização do material de acordo com os objetivos e questões do estudo e definição de unidade de registro e contexto, trechos significativos e categorias; Exploração do material: análise de conteúdos; Tratamento dos resultados obtidos e interpretação: desvendou-se o conteúdo que estava subentendido, determinando características do que estava sendo analisado, sem excluir as informações estatísticas.

Este estudo adotou em todas as suas fases as diretrizes e normas regulamentadoras de pesquisas envolvendo seres humanos que constam na Resolução 466/12 do Conselho Nacional de Saúde ${ }^{(11)}$ e foi aprovado pelo Comitê de Ética em Pesquisa da Universidade Regional do Cariri (URCA) e aprovado com parecer de $n^{\circ}$ 25/2011.

\section{RESULTADOS}

Percebeu-se uma predominância de mulheres na faixa etária compreendida entre 18 e 38 anos, com apenas um filho e católica. A maioria convive em união consensual, é do lar e possui mais de cinco anos de estudo, como também, renda familiar de até um salário mínimo.

Diante dos discursos disponíveis emergiram duas categorias: Contribuição do companheiro na contracepção e $\mathrm{O}$ que as mulheres pensam sobre a participação do homem no Planejamento Familiar (PF)?

As principais formas de colaboração do parceiro na utilização do método consistiram em lembrar o uso quanto aos horários e em provê-los. No entanto, algumas demonstraram acreditar que esta forma de participação está distante das suas expectativas, pois uma contribuição mais efetiva incluiria a ida do companheiro às consultas.

Quanto à percepção feminina sobre a participação de seus parceiros no PF, em sua grande maioria, as participantes relataram considerar importante essa contribuição, ao afirmarem que tanto o ato de engravidar e a criação dos filhos são dependentes de esforços equânimes do casal, e, portanto, esse controle deve ser realizado pelos dois. Porém, mesmo ao afirmarem isso, algumas mostraram aceitação diante da ausência do homem nesse processo. Além disso, encontraram-se posições contrárias a essa participação, tendo em vista que duas mulheres não consideraram importante esse compartilhamento de responsabilidades, atribuindo apenas à mulher esse encargo.

\section{Contribuição do companheiro na contracepção}

Para sete mulheres, a contribuição masculina nesse processo pode ser entendida como a preocupação destes em reforçar os horários de administração do anticoncepcional oral, no intuito de prevenir uma gravidez indesejada:

Ele lembra todos os dias, quer saber se eu to tomando direitinho [...]. (M09)

Ele me lembra, por que eu engravidei da ultima vez por que esqueci de tomar, por isso ele me lembra sempre. (M16)

Conforme percebido nas falas das mulheres, o homem demonstra preocupação com o uso correto do método, advertindo a mulher acerca 
do uso diário, respeitando-se os horários, de forma a garantir que o método tenha eficácia em evitar gravidez subsequente.

Em falas de quatro participantes, a ideia de participação masculina na contracepção, resumese ao ato de prover os métodos, seja pegando-os na unidade de saúde ou na sua falta, comprandoos na farmácia:

Bom, como sou eu que tomo, eu me preocupo mais né? Mas quando eu não posso ir buscar no posto, ele vai. (M05)

Às vezes ele vai buscar no posto, quando não tem lá ele compra. (M08)

Nos discursos de quatro mulheres, a participação masculina foi mencionada de forma mais ampla, como podemos observar a seguir:

Tudo. [...] sempre lembra na hora de usar [camisinha], aceita numa boa usar, porque a gente vê muito por aí homens que não querem usar, mas ele não, ele mesmo não quer que eu tente de novo com os comprimidos, por que ele viu como eu fiquei. Ele nunca reclamou. (M18)

Portanto, conforme evidenciado nas suas considerações, as mulheres acreditam que o uso da camisinha se insere como uma forma de participação mais efetiva do homem uma vez que reconhecem a inexistência dessa prática em outros casais.

Contudo, algumas referem que a contribuição do homem deve ir além da adoção de um método masculino, mas sim sua inclusão nas consultas de PF.

[...] e quando ele podia, ele me acompanhava nas consultas. A gente já conversou também sobre ele fazer vasectomia e ele concorda numa boa [...]. (M03)

Bom, ele usa a camisinha e me apoia com as injeções, só. Ele não vai comigo pras consultas se é isso que você quer saber. (M01)

Três participantes em seus relatos demonstram a ausência da participação masculina nesse processo, seja pelo desejo do homem em ter outro filho, ou pelo fato destes se absterem de participar, como podemos comprovar nas seguintes orações:

Nada! Quando eu vou buscar os comprimidos é a maior briga. Quando eu peço pra ele ir, ele diz que tem mais o que fazer! Ele quer que eu engravide né? (M06)

Conforme expresso pelo segundo discurso, ao definir que a forma de participação do parceiro é "nada" esta mulher poderia estar demonstrando possuir uma expectativa de participação do parceiro que vai além do simples ato de comprar ou buscar no posto.

Nada, só quando falta lá no posto eu peço pra ele ir comprar, aí ele vai, mas às vezes nem isso [...]. (M11)

Duas mulheres demonstraram que, na percepção das mesmas, não há influência significativamente positiva ou negativa no que diz respeito à participação de seus companheiros:

Assim, ele fica na dele, na pausa dos comprimidos a gente não tem relação, pra ele tudo bem [...]. Ele não gosta de usar camisinha. [...] e aquela cirurgia pro homem ele não quer fazer de jeito nenhum. (M14)

Nesse depoimento pode-se perceber a indiferença masculina quanto ao método de contracepção. A mulher, por sua vez, demonstra que o simples fato de seu companheiro aceitar o método é suficiente para que a contracepção seja bem sucedida.

Na verdade ele quer é que eu pare de tomar, por que as vezes ele vê e sabe que eu não estou bem, aí ele pede pra eu parar de tomar a injeção, pra gente continuar só com o preservativo, mas eu não quero, eu não gosto. (M04).

Com o segundo depoimento, percebeu-se que embora o parceiro tenha tido a iniciativa de propor o uso do condom masculino, a favor da saúde da esposa, esta se mostra reticente em trocar de método, por não se sentir confortável com o mesmo. 


\section{O que as mulheres pensam sobre a participação do homem no planejamento familiar?}

Quando indagadas sobre a importância que as participantes atribuíam à participação masculina no PF, 18 manifestaram a relevância destes estarem inseridos no processo:

Eu acho muito importante sim, porque só assim os dois ficam participando, assim a responsabilidade não cai só na mulher, né? (M02)

Eu acho sim muito importante participar junto comigo, a escolha do método é do casal, não de partes isoladas. Entramos nessa juntos, então juntos temos que decidir tudo que envolve a vida de casal, eu tenho que levar em conta a opinião dele, assim como ele tem que levar a minha, $e$ assim a gente decide melhor. (M18)

Eu acho importante até demais, porque eles têm que se posicionar ao lado da mulher, porque a partir do momento que a gente casa, tudo tem que ser decidido entre os dois, eles tem que participar, eles tem que ver o que a gente tá passando. (M04)

Com essas orações fica evidente que, na opinião das mulheres, como elas compartilham uma vida com seus companheiros, as decisões que envolvem o casal também devem sercompartilhadas, devem ser tomadas conjuntamente e, portanto, a escolha do método deve ser uma responsabilidade de ambos, assim a responsabilidade não recairia somente para a mulher.

Além disso, para algumas mulheres, embora a gestação seja um atributo feminino, o ato de engravidar requer a participação de ambas as partes. Logo a decisão da contracepção deve partir dos dois de forma igualitária, já que ambos assumirão as consequências de uma possível gravidez.

Eu acho sim importante, porque assim, se eu vivo com ele, tem que ter a parte dele, né? Eu não engravido sozinha. (M13)

Eu acho importante com certeza porque a escolha não deve ser da mulher, mas sim dos dois, os dois devem conversar e escolher, nenhum dos dois querem ter filhos, né? (M09)
No relato que se segue, fica perceptível que a mulher aponta a importância da participação masculina de forma igualitária tendo em vista que uma gravidez implicaria na necessidade de ambos arcarem com as conseqüências financeiras.

Com certeza, porque hoje em dia, assim, na minha cabeça, as coisas estão muito difíceis, e ter mais filhos nessa dificuldade [financeira] não dá certo, então como a dificuldade fica pros dois, porque os dois vão ter que pagar todas as contas, o certo é os dois terem controle nisso. Eu acho que ficaria muito mais fácil com esse apoio, né? (M11)

[...] Muito importante a participação deles, mas acho muito difícil eles participarem. Eu acho importante porque ficam por dentro dos assuntos os dois, sempre que surgir algum problema os dois vão saber como resolver, mas acho muito difícil isso acontecer. (M01)

Para duas mulheres a inclusão do homem se mostrou desnecessária, afirmando que o encargo da contracepção é de exclusividade feminina, já que são as próprias que gestam e cuidam dos filhos.

Eu acho que não é tão importante ele participar, porque geralmente quem se preocupa com esse assunto é só a mulher, o homem não se preocupa com isso não, se vai ter filho ou não, isso é problema da mulher, geralmente eles são assim, né? Como é ela quem engravida, que vai ter que cuidar do bebê, então é ela que tem que se preocupar. (M15)

Não, acho que não. Eu acho que é uma decisão minha, porque eu acho que é função minha isso. Homem é muito desligado, pra essas coisas. A maioria das vezeséa mulher que toma a decisão, isso não é a toa, não é? Eu me sinto melhor assim. (M16)

\section{DISCUSSÃO}

Algumas mulheres demonstram tomar para si a responsabilidade da contracepção, pelo método ser de uso feminino, assumindo assim esse encargo. Observou-se também o fato do homem prover os métodos, de forma esporádica, uma 
vez que somente na impossibilidade da mulher ir pegar o método no posto de saúde é que ele é acionado a participar, é uma forma suficiente de participação na visão dessas mulheres.

O homem quando compra, lembra ou simplesmente concorda com o uso do método, aparece como aquele que dá suporte ou apoia uma atividade que, supostamente, é da mulher, tendo esta uma atividade mais ativa, principalmente através do uso do contraceptivo oral(7).

As mulheres mostram-se satisfeitas diante da aceitação do uso do preservativo, principalmente por saber que esta não é uma atitude, no ponto de vista das próprias, muito comum entre os homens ${ }^{(12)}$.

Estudos $^{(13-17)}$ encontraram que a atitude do parceiro influencia de forma positiva, por parte das mulheres, na duração e continuidade do uso do método escolhido. Para as mulheres que vão às consultas de PF acompanhadas de seus parceiros, a continuidade e eficácia do método são maiores se comparadas com as que vão desacompanhadas ${ }^{(18)}$.

Estudo que investigou a mesma temática no município de São Paulo identificou que 18,2\% das participantes referiram a inexistência da participação masculina por não haver consenso quanto ao tamanho da prole, destas apenas uma renunciou ao uso de um método contraceptivo feminino, o que, segundo as pesquisadoras, poderia significar que a existência desses métodos permite a mulher manter o controle sobre a sua própria fecundidade ${ }^{(7)}$.

Muitos dos relatos inferiram a negação do homem e transferência para a mulher da exclusividade na opção e utilização do método, negando outras possibilidades que requeiram maior participação dele. Dois problemas que poderiam interferir na autonomia das mulheres para controlar sua fecundidade: a influencia dos homens na escolha do método contraceptivo, e sua negação em participar da anticoncepção, por não aceitarem os métodos masculinos, como o condom e a vasectomia ${ }^{(19)}$.

Curiosamente observou-se na primeira categoria que, na percepção de quinze participantes, seus companheiros contribuíam de alguma forma na utilização do método escolhido. Porém, a maioria das informantes escolheu e utiliza métodos contraceptivos de uso feminino. Este achado corrobora com o estudo que demonstrou que há prevalência de métodos de uso feminino, além da escassa participação masculina na contracepção ${ }^{(5)}$.

Partindo-se da premissa que o interlúdio sexual entre o homem e a mulher tem como resultado natural a concepção, é também de se supor que a decisão de anticoncepção seja feita, naturalmente, de forma igualitária entre os parceiros envolvidos na relação ${ }^{(20)}$. No entanto, a cultura patriarcal ainda se sobrepõe, dando ênfase à responsabilidade feminina no âmbito da contracepção $^{(18)}$.

Percebeu-se em alguns discursos a perspectiva de informantes inseridas no mercado de trabalho mostrando suas preocupações em relação às dificuldades financeiras que surgiriam com a vinda de outro filho, dificuldade que, em sua opinião, deve ser compartilhada com seu cônjuge. As dificuldades financeiras e materiais no que diz respeito à moradia, educação, alimentação e cuidados médicos são um importante incentivo para que os homens e mulheres queiram limitar o número de filhos, de modo a poder proporcionar uma melhor qualidade de vida à família(18)

Todavia, apesar delas referirem a importância da participação, esta opinião, em outros momentos, parece controversa, uma vez que demonstram conformismo, onde algumas mulheres mostraram-se incrédulas diante da possibilidade da inserção do homem nesse compromisso.

As mulheres mostram interesse em uma possível participação mais ativa por parte de seus companheiros e, dessa forma, dividindo a responsabilidade da regulação da fecundidade ${ }^{(21)}$. Contudo, como evidenciado, as próprias se mostram duvidosas quanto a essa divisão igualitária por parte de seus parceiros.

Observa-se a completa aceitação do encargo da contracepção por parte de duas informantes, onde ambas aceitam e assumem essa responsabilidade imposta pelas questões sociais de gênero, justificando que são as próprias que gestam, portanto, tem se ocupar da questão da contracepção, uma vez que essa não é função de seus companheiros, e estes por sua vez se mostram desinteressados no assunto.

Na segunda categoria 18 mulheres mostraramse esclarecidas no que se refere à participação igualitária na contracepção, afirmando a importância da inserção masculina no PF, inclusive 
explicitando uma grande variedade de razões para comprovar essa importância. Porém, essa opinião parece um tanto quanto desconexa, uma vez que a maioria, como visto anteriormente, optou sozinha pelo método em uso, e este sendo, na grande maioria, um método de uso feminino, excluindo assim, seus companheiros desse processo, mostrando, dessa forma, um conformismo feminino quanto a essa realidade desigual de participação da regulação da fecundidade.

Algumas não reconhecem como necessário o envolvimento de seus companheiros na tarefa de contracepção, não havendo uma queixa explicita, mas uma idéia de dispensa do homem nessa atividade, onde essas mulheres assumem esse encargo por uma opção pessoal e/ou por suposições sociais de responsabilidades, referindo essa função como sendo feminina ${ }^{(7)}$.

\section{CONSIDERAÇÕES FINAIS}

Em face do exposto, a pesquisa evidenciou que embora a maioria das participantes tenha demonstrado conhecimento acerca da relevância da participação igualitária dos seus companheiros no controle da fecundidade, uma parcela expressiva das mulheres, referiu não cobrar esse envolvimento. Ao escolher sozinha os métodos, em grande parte de uso feminino, estas mulheres estariam eximindo-os de uma atribuição que deveria ser resolvida conjuntamente. Estas, portanto, estariam assumindo essa responsabilidade de forma exclusiva, mostrando que ainda permanece a ideia socialmente construída, e aceita, consciente ou inconscientemente, pelas mesmas de que é seu papel o de ser encarregada dos assuntos de contracepção, já que, possivelmente, a carga de uma gravidez recairia sobre elas.

A partir de uma análise de todos os discursos, sugere-se que os serviços de saúde devam ir além da distribuição de métodos contraceptivos, devem usar estratégias para atrair a população, oferecendo aos usuários programas educativos em saúde sexual e reprodutiva, informando de forma adequada e eficiente sobre todos os métodos disponíveis, suas vantagens e desvantagens, em especial os de uso masculino, envolvendo ambos os parceiros de forma igualitária nesse processo, enfatizando a questão das responsabilidades, na tentativa de desconstruir assim esse papel socialmente definido de que a mulher, por ser quem gesta, deve ser a encarregada desses assuntos.

Para tanto, o serviço deve dispor de horários convenientes para a população masculina e incentivar sua participação, contribuindo, dessa forma, para que os homens possam assumir sua parcela no encargo da contracepção.

Compreende-se, entretanto, que para essa igualdade ser alcançada deve haver uma abordagem mais ampla, a questão das relações de gênero deve ser abordada primariamente no âmbito educacional, havendo a sensibilização dos mais jovens no que diz respeito a igualdade de gênero, na tentativa de alcançar essa igualdade em todas as esferas da vida, inclusive a reprodutiva. Porém, acredita-se que esses resultados possam contribuir para a construção de uma assistência pautada na participação igualitária de ambos os sexos, promovendo uma prática saudável e efetiva como medida de promoção da saúde na perspectiva do usuário.

\section{REFERÊNCIAS}

1. Bemfam - Sociedade Civil Bem-Estar Familiar no Brasil. O que é o Planejamento Familiar. Rio de Janeiro: Departamento de Informação e Educação; 1980.

2. Galastro EP, Fonseca RMGS. A participação do homem na saúde reprodutiva: o que pensam os profissionais de saúde. Rev. Esc. Enferm. USP. 2005; 41(3):454-9.

3. Santana TCFF. Ações e concepções de planejamento familiar em um sistema local de saúde [dissertação]. Feira de Santana: Universidade Estadual de Feira de Santana (BA); 2004.

4. Ministério da Saúde (BR). Secretaria de Políticas de Saúde. Assistência ao planejamento familiar - Manual Técnico. Brasília: Ministério da Saúde; 1996. 60 p.

5. Penaforte MCLF, Silva LR, Esteves APVS, Silva RF, Santos IMM, Silva MDB. Conhecimento, uso e escolha dos métodos contraceptivos por um grupo de mulheres em uma unidade básica de saúde em Teresópolis, RJ. Cogitare enferm. 2010; (1):124-30.

6. Souza KV, Tyrrell MAR. Os fatos e atos relacionados ao (difícil) exercício dos direitos sexuais e reprodutivos: em recortes, o processo de viver de um grupo de mulheres de classes populares. Texto \& contexto enferm. 2007;16(1): 47-54.

7. Carvalho MLO, Pirotta KCM, SCHOR N. Participação 
masculina na contracepção pela ótica feminina. Rev. Saude Publica. 2001;1(35):23-31.

8. Gonçalves GHT. Laqueadura ou vasectomia: aspectos a considerar antes e após a opção [tese]. Campinas: Faculdade de Ciências Médicas da Universidade Estadual de Campinas; 2003.

9. Polit DF, Beck CT, Hungler BP. Fundamentos de pesquisa em enfermagem: métodos, avaliação e utilização. $7^{\text {a }}$ ed. Porto Alegre: Artmed; 2011.

10. Minayo MCS, Deslandes SF, Neto OC, GOMES R. Pesquisa Social: Teoria, Método e Criatividade. 23a ed. Petrópolis: Vozes; 2004.

11. Ministério da Saúde (BR). Conselho Nacional de saúde. Diretrizes e normas regulamentadoras de pesquisa envolvendo seres humanos. Resolução n. 196 de 10 de outubro de 1996: Brasília; 1996;

12. Silva RM, Araújo KNC, Bastos LAC, Moura ERF. Planejamento familiar: significado para mulheres em idade reprodutiva. Cienc. saude colet. 2011;16(5): 2415-24.

13. Nunes WB, Andrade LDF, Trigueiro JVS, Santos NCCB. Investigação das ações de enfermagem no planejamento familiar em cidades do Curimataú paraibano. Rev. Ciênc. Saúde Nova Esperança. 2013;11(1):31-45.

14. Rodrigues LSA, Rocha RO, Silva MS. Planejamento familiar: percepções de mulheres heterossexuais sobre o papel do casal. Rev enferm UFPE on line. 2014; 8(2):323-9.

15. Lima VC. Ausência dos usuários homens na atenção primária: revisão integrativa. Revista Formar Interdisciplinar. 2013; 1(2):42-50.

16. Gomes R, Moreira MCN, Nascimento EF, Rebello LEFS, Couto MT, Schraiber LB. Os homens não vêm! Ausência e/ou invisibilidade masculina na atenção primária. Cienc. saude colet. [online]. 2011;16(1):983-92.

17. Costa AM. Planejamento familiar no Brasil. Rev. Bioet. 2009, 4(2).

18. Marcolino C, Galastro EP. As visões feminina e masculina acerca da participação de mulheres e homens no planejamento familiar. Rev. Latino-Am. Enfermagem. 2001;9(3):77-82.

19. Prates CS, Abib GMC, Oliveira DLLC. Poder de gênero, pobreza e anticoncepção: vivências de multíparas. Rev. gauch. enferm. 2008; 29(4):604-11.

20. Dantas LA, Andrade LDF, Lima GMB, Saraiva AM. O desabrochar das flores: opiniões de adolescentes grávidas sobre planejamento familiar. Cogitare enferm. 2013;18(3):502-8.
21. Silva RM, Araújo KNC, Bastos LAC, Moura ERF. Planejamento familiar: significado para mulheres em idade reprodutiva. Cienc. saude colet. 2011;16(5):415-24. 